Chapman University

Chapman University Digital Commons

Pharmacy Faculty Articles and Research

School of Pharmacy

2007

\title{
Four Novel Co-Precipitation Procedures for the Synthesis of Lanthanum-Strontium Manganites
}

Vuk Uskoković

ChapmanUniversity, uskokovi@chapman.edu

Miha Drofenik

Jožef Štefan Institute

Follow this and additional works at: http://digitalcommons.chapman.edu/pharmacy_articles

Part of the Materials Chemistry Commons, Nanotechnology Commons, and the Other Chemistry Commons

\section{Recommended Citation}

Uskoković, V., Drofenik, M., 2007. Four novel co-precipitation procedures for the synthesis of lanthanum-strontium manganites. Materials \& Design 28, 667-672. doi:10.1016/j.matdes.2005.07.002

This Article is brought to you for free and open access by the School of Pharmacy at Chapman University Digital Commons. It has been accepted for inclusion in Pharmacy Faculty Articles and Research by an authorized administrator of Chapman University Digital Commons. For more information,

please contact laughtin@chapman.edu. 


\section{Four Novel Co-Precipitation Procedures for the Synthesis of Lanthanum- Strontium Manganites}

\section{Comments}

NOTICE: this is the author's version of a work that was accepted for publication in Materials \& Design. Changes resulting from the publishing process, such as peer review, editing, corrections, structural formatting, and other quality control mechanisms may not be reflected in this document. Changes may have been made to this work since it was submitted for publication. A definitive version was subsequently published in Materials \& Design, volume 28, in 2007. DOI: 10.1016/j.matdes.2005.07.002

The Creative Commons license below applies only to this version of the article.

\section{Creative Commons License}

\section{(c) 1 (1) 90}

This work is licensed under a Creative Commons Attribution-Noncommercial-No Derivative Works 4.0 License.

\section{Copyright}

Elsevier 


\title{
Four Novel Co-Precipitation Procedures for the Synthesis of Lanthanum-Strontium Manganites
}

\author{
Vuk Uskoković ${ }^{1}$, Miha Drofenik ${ }^{1,2}$ \\ ${ }^{1}$ Advanced Materials Department, Jožef Stefan Institute, Jamova 39, Ljubljana, Slovenia \\ ${ }^{2}$ Faculty of Chemistry and Chemical Engineering, University of Maribor, Smetanova 17, Maribor, Slovenia
}

\begin{abstract}
Lanthanum-strontium manganites were synthesized using co-precipitation method with a reverse micellar microemulsion. Either oxalic acid, sodium hydroxide or tetramethylammonium hydroxide was used for the precipitation of precursor cations in a form that was subsequently calcined under various conditions in order to obtain perovskite manganite phase. Correlations between the properties of the synthesized powder and the calcination conditions have been put forth. The properties of the microemulsion-assisted synthesized material were compared with the samples prepared by following the supposedly similar chemical recombinations in bulk solutions, with an aim to challenge the fact that microemulsions in general have only templating effects on the morphology of co-precipitated powder. TEM measurements, X-ray diffraction analyses and magnetic measurements were used in order to gain an insight into the mentioned difference, which is an important one for the future understanding of the role that reverse micelles play in the processes of materials synthesis.
\end{abstract}

Corresponding author: vuk.uskokovic@ijs.si

Keywords: A. nano materials B. particulates and powders E. magnetic

\section{Introduction}

Lanthanum-strontium manganites belong to the family of attractive magnetic ceramics for the contemporary electronic industry, due to the wide range of potential applications that these materials might possess ${ }^{1}$, depending largely on the method of synthesis performed ${ }^{2}$. High electrical conductivity ${ }^{3}$ - as exploited in solid oxide fuel cells; catalytic activity $^{4,5}$ - suited for waste gas purification and catalytic combustion processes; colossal, giant, or low-field magnetoresistance ${ }^{6}$; and relatively low Curie temperature ${ }^{2}-$ interesting for biomedical applications, are some of the typical properties that caught scientific attention to these materials.

Reverse micellar synthesis of materials is since $1982^{7}$ known as a viable method for producing relatively uniform and monodispersed particles. Direct correlations between size of the reverse micelles - as nano-sized multimolecular structures existing at particular compositional range of microemulsions, and size of the particles prepared within, were proposed ${ }^{8,9}$. However, a number of recent studies ${ }^{10,11}$ have indicated that such oversimplified correlations (especially when aimed at reaching a generalized character) could not be justified ${ }^{12}$, and that dynamic, non-linear, and rich in molecular species- interactional character introduces much more complexities (than proposed within the routinely used correlations) and in most cases, as of today's knowledge on the field, 
necessitates a trial-and-error approach in the processes of materials design by using reverse micelles.

Four different wet, co-precipitation approaches to the synthesis of lanthanumstrontium manganites were performed within this work. With an aim of a clearer and more concise presentation of the part of the obtained results, comparison of the methods that included the presence of a reverse micellar microemulsion with the ones excluding it, has been used.

\section{Experimental Procedure}

Two pairs of correspondent co-precipitation approaches - being different in the precipitation agent used - were followed in the process of the synthesis of lanthanumstrontium manganites with the desired stoichiometric formula of $\mathrm{La}_{0.67} \mathrm{Sr}_{0.33} \mathrm{MnO}_{3+\delta}$. In each case of the synthesis, two solutions were mixed at room temperature and aged for 1 $\mathrm{h}$ in case of the microemulsion-assisted hydroxide-co-precipitation synthesis, and for $3 \mathrm{~h}$ in all of the three other synthesis approaches. Centrifugation was used for the sedimentation of the dispersed, solid phase, which is then repeatedly washed, dried and calcined in air at various temperatures. The produced powders were characterized by performing TEM measurements (JEOL JEM-2000FX), X-ray diffraction analyses (D4 Endeavor), and magnetic measurements (Manics DSM10). The solutions used to initiate the precipitation reactions were:

i) In case of the bulk hydroxide-co-precipitation synthesis ${ }^{8}$, the first solution comprised $3 \mathrm{ml}, 2 \mathrm{ml}$ and $1 \mathrm{ml}$ of $0.5-\mathrm{M}$ aqueous solutions of $\mathrm{MnCl}_{2}, \mathrm{La}\left(\mathrm{NO}_{3}\right)_{3}$ and $\mathrm{Sr}\left(\mathrm{NO}_{3}\right)_{2}$, respectively, whereby the second solution comprised $20 \mathrm{ml}$ of $1 \mathrm{M}$ aqueous solution of $\mathrm{NaOH}$.

ii) In case of the microemulsion-assisted hydroxide-co-precipitation synthesis ${ }^{13}$, the first solution comprised 0.076-M overall precursor cation concentration (molar ratio of $\mathrm{Mn}^{2+}: \mathrm{La}^{3+}: \mathrm{Sr}^{2+}=47.4: 31.6: 21$ ) aqueous solution (formed by using $\mathrm{MnCl}_{2}$, $\mathrm{La}\left(\mathrm{NO}_{3}\right)_{3}$ and $\mathrm{Sr}\left(\mathrm{NO}_{3}\right)_{2}$ as precursor salts) within CTAB:1-hexanol:1-butanol: $\mathrm{H}_{2} \mathrm{O}=32.3$ : 15.2 : 22.2 : 30.3 (wt\%) microemulsion, whereby the second solution comprised microemulsion of the same composition carrying $0.5-\mathrm{M}$ aqueous solution of $\left(\mathrm{CH}_{3}\right)_{4} \mathrm{NOH}$, the weight ratio of the precipitating microemulsion vs. the precursor microemulsion being 1.355 .

iii) In case of the bulk oxalate-co-precipitation synthesis, the first solution comprised $6 \mathrm{ml}$ of hydroalcoholic solution $\left(\mathrm{C}_{2} \mathrm{H}_{5} \mathrm{OH}: \mathrm{H}_{2} \mathrm{O}=1: 2\right.$, volume ratio) of precursor cations ( $\mathrm{Mn}: \mathrm{La}: \mathrm{Sr}=4.6: 2.2: 1$, molar ratio), whereby the second solution comprised $0.84-\mathrm{M}$ oxalic acid, with 1.1 being the volume ratio of the second solution to the first one.

iv) In case of the microemulsion-assisted oxalate-co-precipitation synthesis, the first solution comprised aqueous solution of $\mathrm{MnCl}_{2}, \mathrm{La}\left(\mathrm{NO}_{3}\right)_{3}$, and $\mathrm{Sr}\left(\mathrm{NO}_{3}\right)_{2}$ - with the resulting cation concentration of $0.5 \mathrm{M}$ and the molar ratio of $\mathrm{Mn}^{2+}: \mathrm{La}^{3+}: \mathrm{Sr}^{2+}=5: 2: 1$ - within CTAB : 1-hexanol : $\mathrm{H}_{2} \mathrm{O}$ microemulsion (CTAB : 1-hexanol: $\mathrm{H}_{2} \mathrm{O}=29.7$ : 55.1 : 15.2 weight ratio), whereby the second solution comprised the microemulsion of the same composition carrying 0.84-M aqueous solution of oxalic acid. The weight ratio between precursor and precipitating microemulsion was set to 1.5. 
The reason for the use of $\mathrm{NaOH}$ as the precipitating agent within the bulk hydroxide-co-precipitation synthesis was that, somehow, monophase desired products could not have been obtained with using tetramethylammonium hydroxide as the precipitating agent in bulk conditions. The reason for the use of hydroalcoholic solution in case of the bulk oxalate-co-precipitation synthesis lies in the fact that in the presence of $\mathrm{NO}_{3}{ }^{-}, \mathrm{Mn}^{2+}$ in pure aqueous solution forms complexes together with $\mathrm{C}_{2} \mathrm{O}_{4}{ }^{2-}$ and thus resists the precipitation in form of hydroxides. These differences are significant since they include important obstacles in bringing about correlations between the corresponding procedures, from which the role of the reverse micelles, as proposed within this work, might more clearly emanate.

\section{Results and Discussion}

The difference in the mechanism of the formation of LaSr-manganite between bulk- and microemulsion-assisted- prepared powders when using hydroxides coprecipitation approach, during the annealing can be observed by comparing XRD patterns presented in Fig. 1. Whereas in case of the bulk synthesis, growth of $\mathrm{SrCO}_{3}$ crystallites comprising the as-dried powder as well as the transformation of $\mathrm{La}(\mathrm{OH})_{2}$ into $\mathrm{La}_{2} \mathrm{O}_{2} \mathrm{CO}_{3}$ is evident from comparing the XRD patterns (a) and (b), the transformation of qualitatively identical as-dried powder as prepared in microemulsion into an amorphous, more homogenous transient composition, is obvious by comparing XRD patterns (a) and (c). Both powders after heating for $2 \mathrm{~h}$ in air at $\geq 600{ }^{\circ} \mathrm{C}$ yield manganite perovskite samples, whereas the changes in crystal structure, going from tetrahedral to orthorombic followed by the increase in La stoichiometric proportion and the decrease in $\mathrm{Mn}$ proportion (due to the compensation of charges), with XRD-determined average particle size kept constant, are noticed with the increase in the temperature of calcination in the case of the bulk-synthesized sample, only increase in average particle size with calcination temperature is noticed in case of the microemulsion-assisted-synthesized sample, obviously due to the more homogenous re-crystallization processes for the latter as-dried composition into the manganite phase. Analytically determined stoichiometric formula of the compound prepared in microemulsion and calcined at $1100{ }^{\circ} \mathrm{C}$ was $\mathrm{La}_{0.59} \mathrm{Sr}_{0.41} \mathrm{Mn}_{0.99} \mathrm{O}_{3+\delta}$.

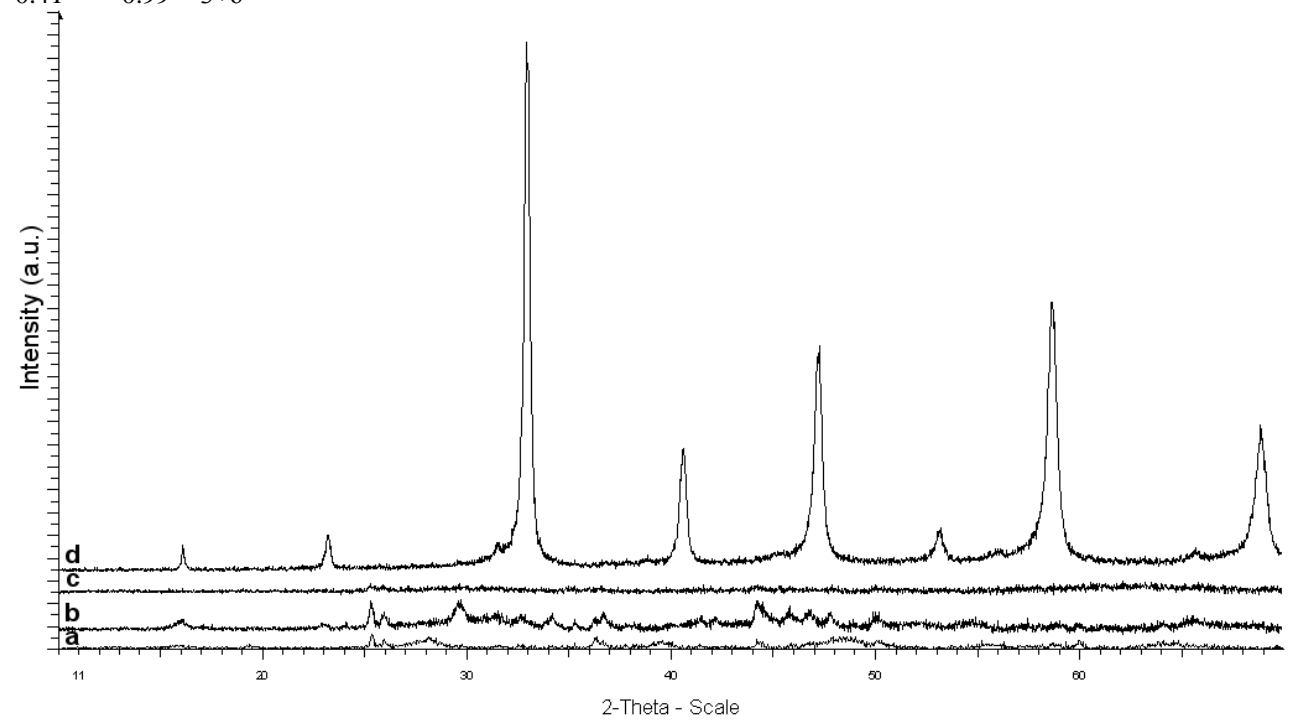


Fig. 1. XRD patterns of the as-dried powder synthesized by hydroxide co-precipitation procedure in solution (a), the same powder calcined at $450{ }^{\circ} \mathrm{C}$ (b) and $600{ }^{\circ} \mathrm{C}$ (d) for $2 \mathrm{~h}$ in air and of the sample coprecipitated within hydroxide approach in reverse micelles and calcined at $450{ }^{\circ} \mathrm{C}$ in air for $2 \mathrm{~h}$ (c).

In case of the oxalate co-precipitation method, when the approach in the hydroalcoholic, bulk solution is followed, the process of the manganite formation follows more homogenous route when compared to the microemulsion-assisted procedure. In case of the bulk synthesis, a mostly amorphous transient structure is detected at $500{ }^{\circ} \mathrm{C}$ (Fig. 2a), whereby after annealing at the same conditions, transient phases of $\mathrm{La}_{2} \mathrm{O}_{2} \mathrm{CO}_{3}$ and cubic $\mathrm{Mn}_{2} \mathrm{O}_{3}$ are detected in case of the microemulsion synthesis (Fig. 2b). The formation of the manganite is completed after heat treatment at $\geq 1000{ }^{\circ} \mathrm{C}$ under given conditions (annealing in air for $2 \mathrm{~h}$, with heating rate of $10^{\circ} \mathrm{C} / \mathrm{min}$ ) in case of the latter approach (Fig. 2d), whereby $700{ }^{\circ} \mathrm{C}$ is sufficient temperature for the desired manganite formation in case of the synthesis in hydroalcoholic solution (Fig. 2c). It is important to note that qualitatively different powders were obtained as the products of the precipitation reactions in these two comparative cases, as detected by XRD analyses.

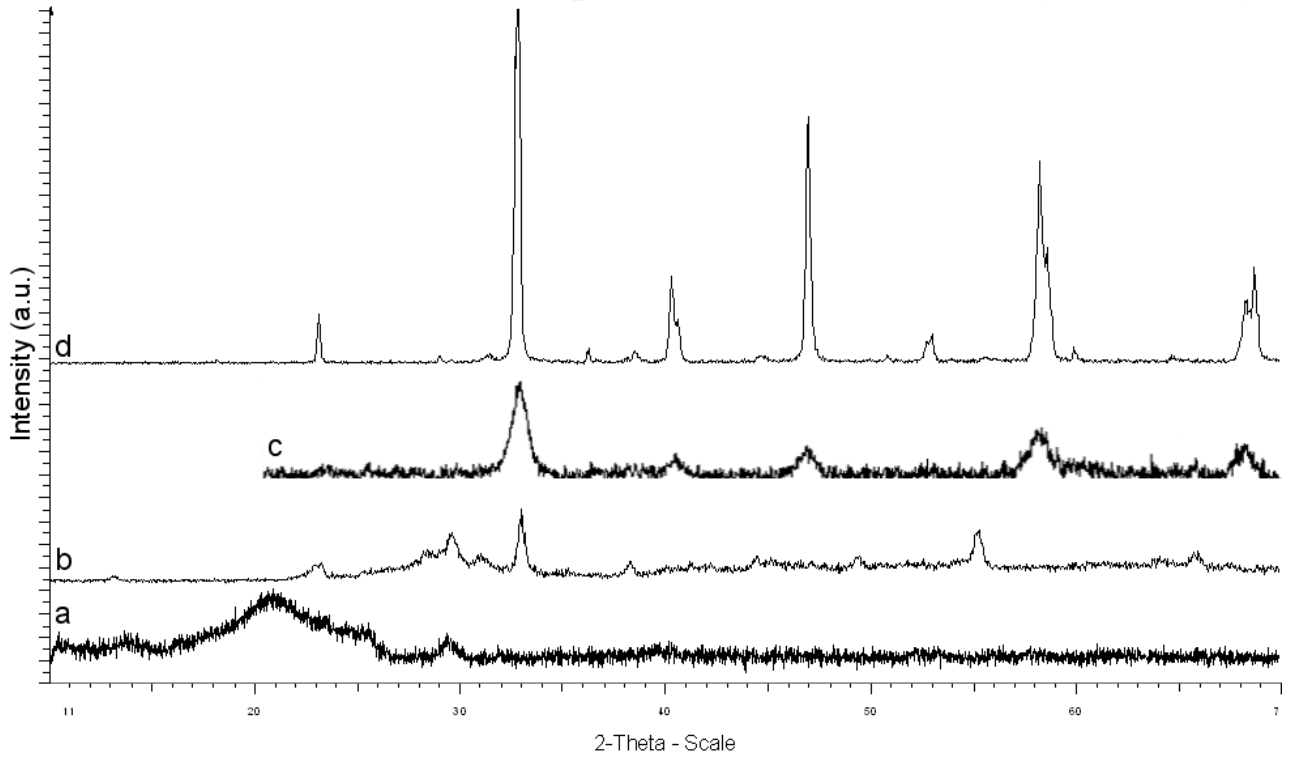

Fig. 2. Normalized XRD patterns of the samples synthesized using oxalate co-precipitation approach in bulk solution (a, c) and in microemulsion (b, d), annealed at $500{ }^{\circ} \mathrm{C}$ (a, b), $700{ }^{\circ} \mathrm{C}$ (c) and $1000{ }^{\circ} \mathrm{C}$ (d) for $2 \mathrm{~h}$ in air.

The dependencies of the average particle sizes (as determined by using DebyeScherrer's equation) vs. calcination temperature for the samples synthesized by all of the four methods of preparation presented here, are shown in Fig. 3. Continually increasing average particle size with calcination temperature is observed in cases of the samples precipitated by following microemulsion-assisted hydroxide- and bulk oxalate coprecipitation procedures. In case of the microemulsion-assisted oxalate-co-precipitation procedure of synthesis, the monophase product is formed only at temperatures exceeding or equal to $1000{ }^{\circ} \mathrm{C}$ under given annealing conditions, with constant average particle size after calcination at both 1000 and $1100{ }^{\circ} \mathrm{C}$, whereas fluctuations in particle size observed in the case of the sample prepared by performing bulk hydroxide-co-precipitation are ascribed to crystal structure distortions that in this case take place during the annealing. 


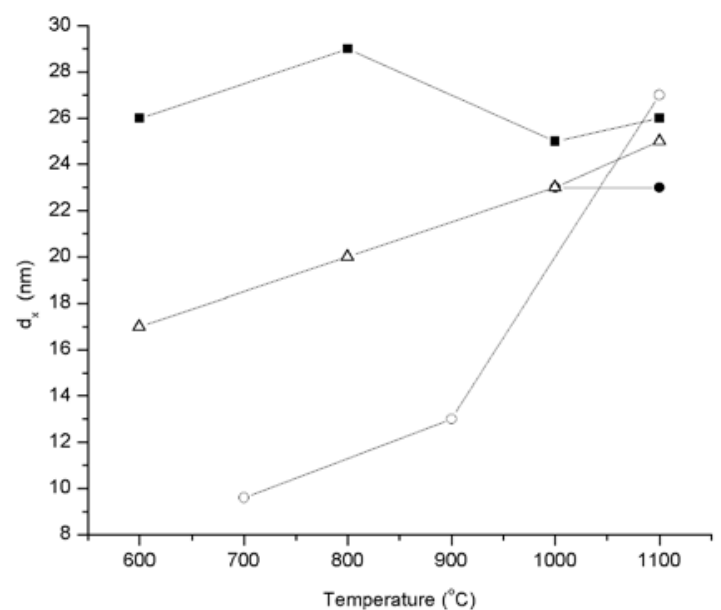

Fig. 3. Dependencies of the average particle sizes vs. calcination temperature for the samples synthesized by performing the bulk hydroxide-co-precipitation procedure (-ם-), the microemulsion-assisted hydroxideco-precipitation procedure (- $\Delta-)$, the bulk oxalate-co-precipitation (-o-), and the microemulsion-assisted oxalate-co-precipitation procedure of synthesis (-๑-). The lines are used only as a guide to an eye.

The measured saturation magnetization vs. calcination temperature dependencies are presented in Fig. 4. Improved resulting double-exchange interaction that leads to the gradual rise in magnetization values is attributed to increasing average particle size for all the samples except for the sample synthesized by hydroxide precursor method in solution, where crystal structure modifications are taken as the major reason for an almost linear dependency of magnetization vs. calcination temperature. Mutual increase in XRDdetermined average particle size and saturation magnetization with the increase in calcination time for the sample obtained by following bulk oxalate co-precipitation approach and calcination at $700{ }^{\circ} \mathrm{C}$, is presented in Fig. $4 \mathrm{~b}$.

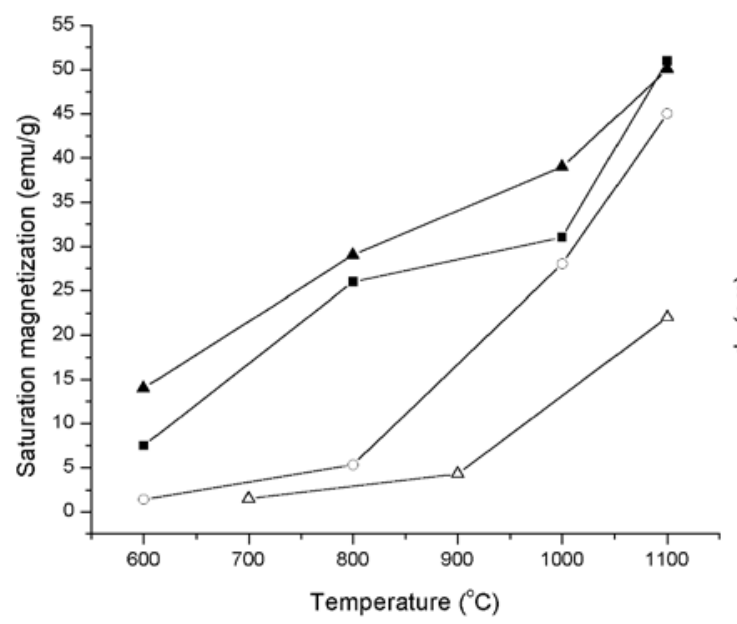

a.)

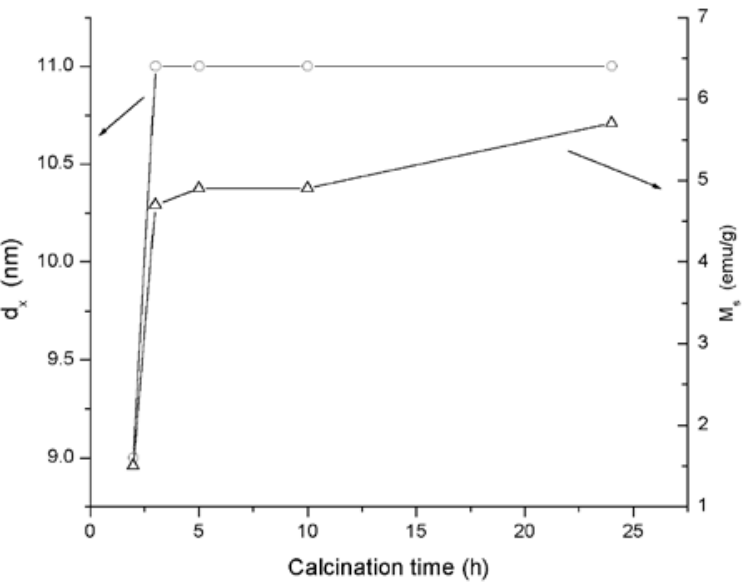

b.)

Fig. 4. a) Saturation magnetization vs. calcination temperature for the sample synthesized within bulk- (- $\Delta-$ ) and microemulsion-assisted (-o-) oxalate co-precipitation approach, and bulk- (- $\mathbf{\Delta}-)$ and microemulsionassisted (-m-) hydroxide co-precipitation approach. b) Dependencies of average particle size $\left(\mathrm{d}_{\mathrm{x}}\right)$ and saturation magnetization $\left(\mathrm{M}_{\mathrm{s}}\right)$ vs. calcination time for the sample synthesized by performing bulk oxalate co-precipitation approach and calcined at $700{ }^{\circ} \mathrm{C}$. 
The dependencies of the saturation magnetization vs. measuring temperature for the sample synthesized by following microemulsion-assisted hydroxide co-precipitation approach, and annealed at 800, 1000, and $1100{ }^{\circ} \mathrm{C}$, are shown in Fig. 5a. By using extrapolation technique, Curie point was found to be independent on the calcination temperature, at $\sim 110{ }^{\circ} \mathrm{C}$ in all the three cases. Saturation magnetization vs. measuring temperature dependencies for the samples annealed at $1100^{\circ}$, whereas prepared by following all of the four presented methods of synthesis, are shown in Fig. 5b. Whereas microemulsion-assisted synthesized samples exhibit Curie point at $\sim 110{ }^{\circ} \mathrm{C}$, the samples prepared by following bulk co-precipitation approaches have lower Curie point at $\sim 95$ ${ }^{\circ} \mathrm{C}$.

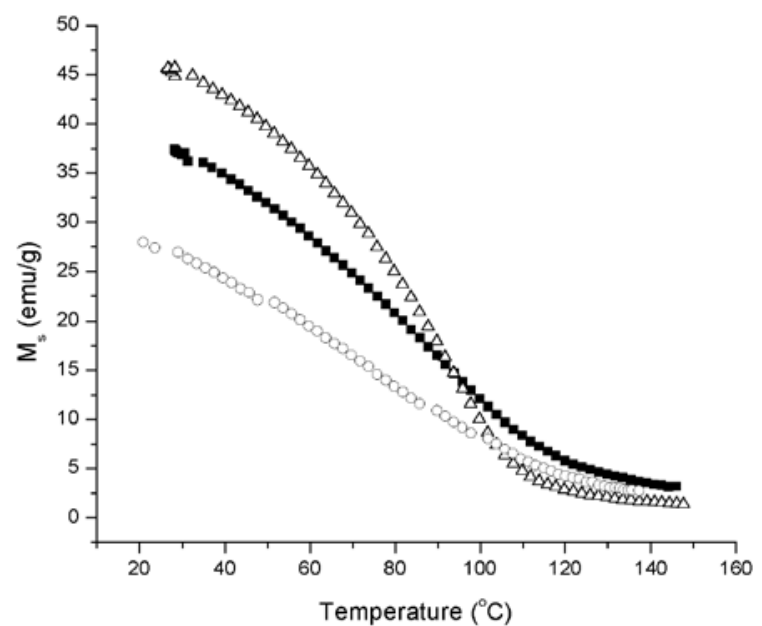

a.)

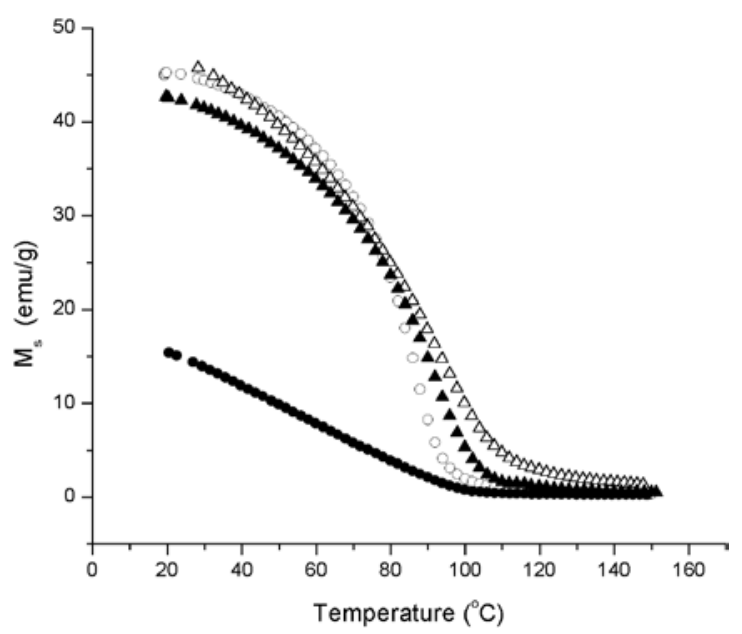

b.)

Fig. 5. The dependencies of the saturation magnetization vs. measuring temperature for a.) the sample synthesized by following microemulsion-assisted hydroxide co-precipitation approach, and annealed at 800 (o), $1000(\boldsymbol{\bullet})$, and $1100{ }^{\circ} \mathrm{C}(\Delta)$; b.) the samples synthesized by using bulk (o) and microemulsion-assisted $(\Delta)$ hydroxide co-precipitation approaches and bulk $(\bullet)$ and microemulsion-assisted $(\boldsymbol{\Delta})$ oxalate coprecipitation approaches, annealed at $1100{ }^{\circ} \mathrm{C}$ in air for $2 \mathrm{~h}$.

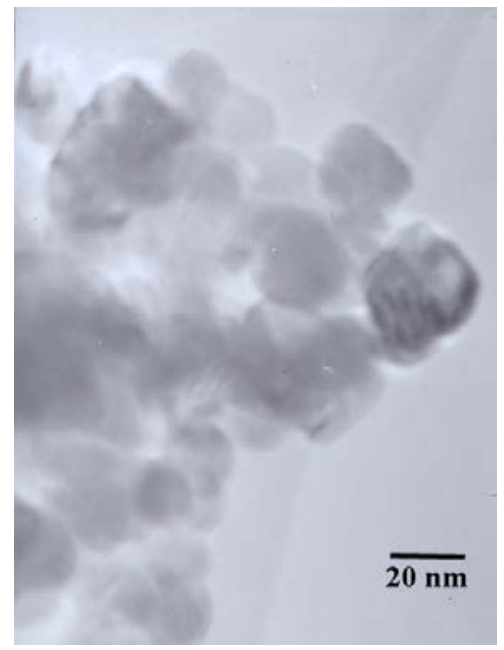

a.)

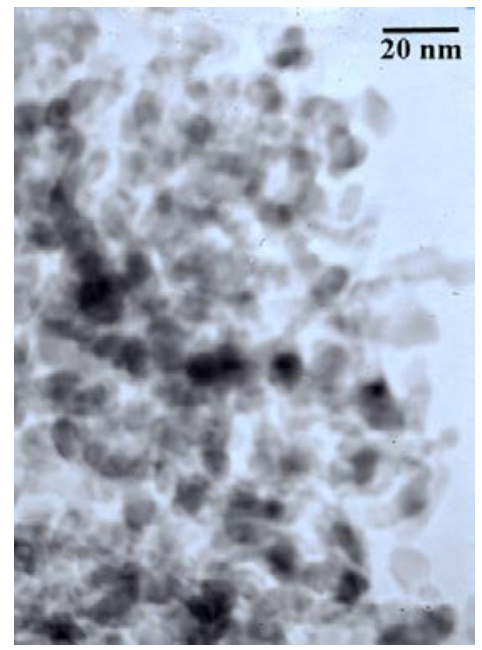

b.)

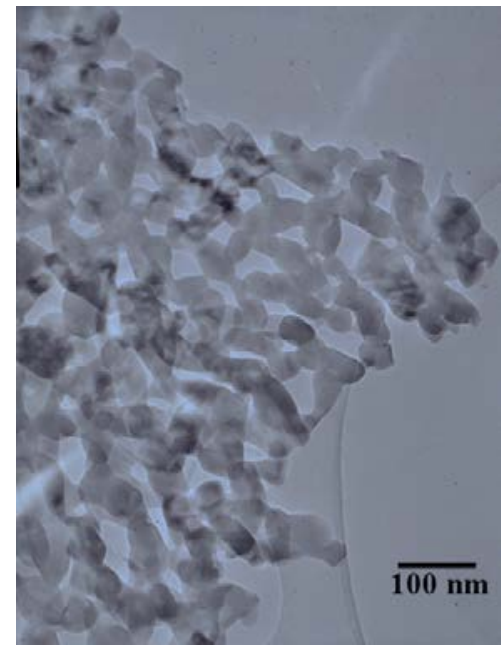

c.) 


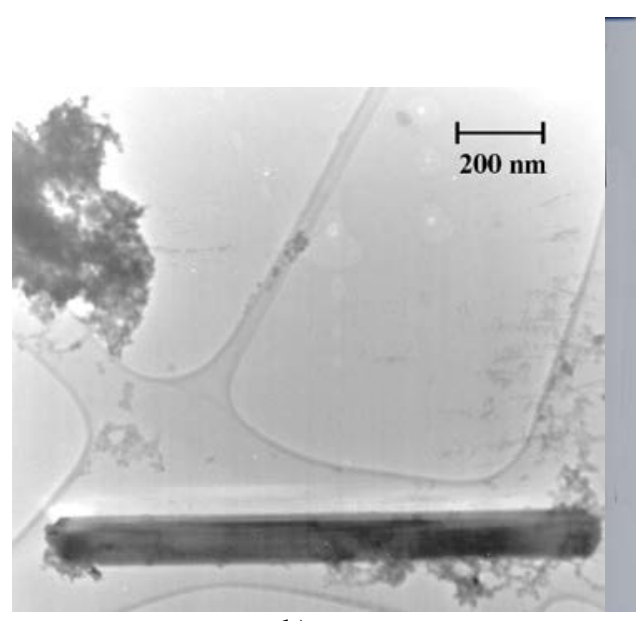

d.)

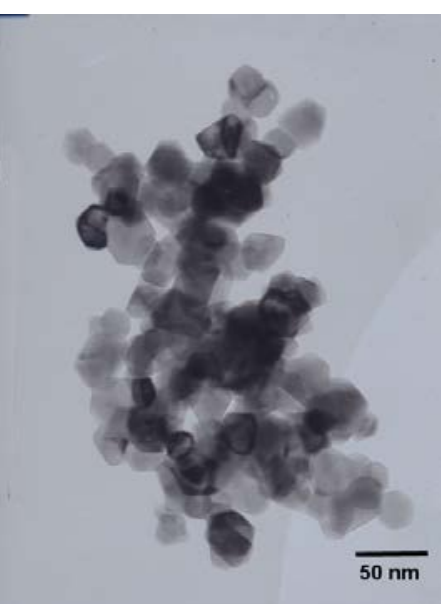

e.)

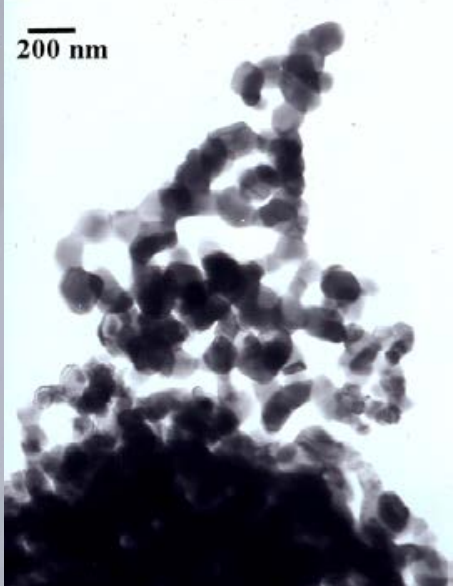

f.)

Fig. 6. TEM images: of the sample synthesized by performing the bulk- (a) and the microemulsion-assisted (b) hydroxide co-precipitation approach and calcined at $600{ }^{\circ} \mathrm{C}$ in air for $2 \mathrm{~h}$; of the sample synthesized by performing the bulk oxalate co-precipitation approach and calcined at $700{ }^{\circ} \mathrm{C}$ for $3 \mathrm{~h}$ (c), at $700{ }^{\circ} \mathrm{C}$ for $24 \mathrm{~h}$ (d), and at $1100{ }^{\circ} \mathrm{C}$ for $2 \mathrm{~h}$ (e); of the sample synthesized by following the microemulsion-assisted oxalate co-precipitation approach and calcined at $1000{ }^{\circ} \mathrm{C}$ for $2 \mathrm{~h}(\mathrm{f})$.

From the TEM images presented in Fig. 6, the differences in morphology between the LaSr-manganite samples prepared by following hydroxide co-precipitation procedure within bulk and microemulsion conditions are obvious. Whereby the sample prepared in bulk conditions is typical of its wide distribution of particle sizes (Fig. 6a), the sample prepared in microemulsion consists of much narrower particle size distribution (Fig. 6b), due to much closer conditions for each nucleus formation and subsequent grain growth for each particle in the latter case. Relatively monodisperse particles obtained from the bulk oxalate co-precipitation approach when calcination was performed at $700{ }^{\circ} \mathrm{C}$ for $3 \mathrm{~h}$, exhibiting saturation magnetization of $5 \mathrm{emu} / \mathrm{g}$, are presented in Fig. 6c. Rod-shaped particles with more than $1 \mu \mathrm{m}$ in length and approximately 10 times less in width on average, are formed after annealing at the same temperature for $24 \mathrm{~h}$, as is evident from Fig. 6d. Particles of similarly narrow particle size distribution, but of a larger degree of agglomeration are obtained from the bulk oxalate co-precipitation approach and calcination at $1100{ }^{\circ} \mathrm{C}$ for $2 \mathrm{~h}$ (Fig. 6e). TEM image of the manganite sample comprising narrowly distributed particles regarding their sizes, but agglomerated to a large extent, obtained by the microemulsion-assisted oxalate co-precipitation approach and calcination at $1000{ }^{\circ} \mathrm{C}$ for $2 \mathrm{~h}$, is presented in Fig. $6 \mathrm{f}$.

In our previous work $^{14}$ we showed that introducing a reverse micellar microemulsion in the process of an in situ precipitation synthesis of NiZn-ferrite, lead to the formation of a different product (NiZn-ferrite instead of $\delta-\mathrm{FeOOH}$ ), which induced a general conclusion that reverse micelles cannot be considered as chemically inert nanoreactors, but rather as complex multimolecular entities physicochemically actively engaged in the pathways of materials preparation. Thus, different nano-structures as obtained herein in both pairs of comparative co-precipitation procedures within reactions of similar reactants, leading to different mechanisms of manganite formation during the annealing, is not surprising and might have the presence (or absence) of the reverse micelles as its major cause. However, the usage of different reactants in case of the comparison within hydroxide-precursors approaches, as well as the usage of different 
solution medium in case of the oxalate-precursors procedures, leaves enough explanation space for these differences (beside effect of the microemulsion only) to have effects on the observed powders' morphological, compositional and structural differences, as well as the differences in the pathways of formation, presented herein.

\section{Conclusions}

The differences in the products properties, together with different mechanisms of the desired lanthanum-strontium manganite formation, whether the syntheses were performed in aqueous (or hydroalcoholic) solutions or in reverse micellar microemulsions, were identified and laid out within the previous section. In general, microemulsions can again ${ }^{15}$ be regarded as not having only templating effects upon the precipitated powder morphology - as is obvious in comparing cases of hydroxide coprecipitation approaches, but due to complex physicochemical interactions that they support as a medium for the materials synthesis, they can influence the identity of the precipitated product as well - as is obvious in comparing cases of oxalate co-precipitation approach, in both cases having large influence on the pathways of the designed material formation during the high-temperature processing, when comparing to the bulk synthesis cases that exclude their presence in the preparation procedures.

\section{References}

[1] Coey JMD, Viret M, Molnar SV. Mixed-Valence Manganites. Adv Phys 1999; 48 (2) $167-293$.

[2] Licci F, Turilli G, Ferro P, Ciccarone A. Low-Temperature Synthesis and Properties of $\mathrm{LaMnO}_{3}$ and $\mathrm{La}_{0.67} \mathrm{R}_{0.33} \mathrm{MnO}_{3}(\mathrm{R}=\mathrm{Ca}, \mathrm{Sr}, \mathrm{Ba})$ from Citrate Precursors. J Am Ceram Soc 2003; 86 (3) 413 - 19.

[3] Lavrikov AS, Sevastyanov VV, Nikitin SV, Ivanov-Shitz AK. Sintez $\mathrm{La}_{0.74} \mathrm{Sr}_{0.26} \mathrm{MnO}_{3}$ s Povishenoy Elektroprovodnostyu. Neorg Mater 2004; 40 (5) 606 - 10.

[4] Giannakis AE, Ladavos AK, Pomonis PJ. Preparation, Characterization and Investigation of Catalytic Activity for $\mathrm{NO}+\mathrm{CO}$ Reaction of $\mathrm{LaMnO}_{3}$ and $\mathrm{LaFeO}_{3}$ Perovskite Prepared via Microemulsion Method. Appl Cat B: Env 2004; 49: 147 - 58.

[5] Bell RJ, Miller GJ, Drennan J. Influence of Synthesis Route on the Catalytic Properties of $\mathrm{La}_{1-\mathrm{x}} \mathrm{Sr}_{\mathrm{x}} \mathrm{MnO}_{3}$. Solid State Ionics 2000; 131: 211 - 20.

[6] Nagaev EL. Colossal-Magnetoresistance Materials: Manganites and Conventional Ferromagnetic Semiconductors. Phys Rep 2001; 346: 387 - 531.

[7] Boutonnet M, Kizling J, Stenius P. The Preparation of Monodisperse Colloidal Metal Particles from Micro-Emulsions. Coll Surf 1982; 5 (3) 209 - 25.

[8] Pileni MP, Zemb T, Petit C. Solubilization by Reverse Micelles: Solute Localization and Structure Perturbation. Chem Phys Lett 1985; 118 (4) 414 - 20.

[9] O'Connor CJ, Kolesnichenko V, Carpenter E, Sangregorio C, Zhou W, Kumbhar A, Sims J, Agnoli F. Fabrication and Properties of Magnetic Particles with Nanometer Dimensions. Synth Met 2001; 122: 547 - 57.

[10] Hua R, Zang C, Shao C, Xie D, Shi C. Synthesis of Barium Fluoride Nanoparticles from Microemulsion. Nanotechnology 2003; 14: 588 - 91.

[11] Lin JC, Dipre JT, Yates MZ. Microemulsion-Directed Synthesis of Molecular Sieve Fibers. Chem Mater 2003; 15: 2764 - 73. 
[12] Natarajan U, Handique K, Mehra A, Bellare JR, Khilar KC. Ultrafine Metal Particle Formation in Reverse Micellar Systems: Effects of Intermicellar Exchange on the Formation of Particles. Langmuir 1996; 12: 2670 - 8.

[13] Uskoković V, Makovec D, Drofenik M. Synthesis of Lanthanum-Strontium Magnanites by a Hydroxide-Precursor Co-Precipitation Method in Solution and in Reverse Micellar Microemulsion. Mat Sci Forum 2005; 494: 155 - 60.

[14] Uskoković V, Drofenik M. A Mechanism for the Formation of Nanostructured NiZn Ferrites via a Microemulsion-Assisted Precipitation Method. Coll Surf A: Phys Eng Asp 2005, submitted.

[15] Shchukin DG, Sukhorukov GB. Nanoparticle Synthesis in Engineered Organic Nanoscale Reactors. Adv Mater 2004; 16 (8) 671 - 82. 